\title{
Cytogenetic Response Assessment to Imatinib Mesylate Therapy for Chronic Myeloid Leukemia in Iraqi Patients
}

\author{
Azhar M Haleem $(\mathrm{PhD})^{1}$
}

Abstract

Background:Chronic Myeloid Leukemia (CML) is a disorder in myeloproliferative pluripotent hematopoietic primogenitor cells distinguished by huge reproduction of myeloid cells. CML cytogenetic distinguished by reciprocal translocation between the long arms of chromosomes 9 and 22 - to produce hallmark Philadelphia chromosome.

Objective: The main goal of the current study was to identify the secondary chromosomal aberrations associated with the CML in Iraqi patients have positive $\mathrm{Ph}$ - chromosome using Imatinib theraby, at different phases of the disease.

Patients and Methods: Practical part of this study was conducted from April/2018 to October/ 2019 in the Al-Kadumyha Teaching Hospital and Tissue Culture and Immunochemistry Lab/ University of Technology, for $\leq 18$ years age for $75 \mathrm{CML}$ eligible patients. Karyotypes of Philadelphia chromosome-positive bone marrow samples were examined for CML patients which were used Imatinib every twelve weeks. Secondary chromosomal abnormalities associated with development of disease were detected and calculated.

Results: The average age of patients was $42 \pm 8.7$ years, while male to female ratio was (1.7:1), males number were 48 with percentage about 64\%, while females number were 27 with percentage $36 \%$, only $89.3 \%$ of CML patients showed a typical shape of $\mathrm{Ph}$ - chromosome, $\mathrm{t}(9$ : 22)(q34:q11.2), while 27 of 75 showed real cytogenetic response to Imatinib therapy. Conclusion: CML patients with high secondary chromosomal aberrations revealed low cytogenetic and molecular response to imatinib therapy, especially in blast phase. Keywords:Chronic Myeloid Leukemia, BCR/ALB gene, Imatinib, Chromosomal Aberrations, FISH.

Corresponding Author: amhjanabi74@gmail.com

Received: $19^{\text {th }}$ January 2020

Accepted: $12^{\text {th }}$ March 2020

DOI:https://doi.org/10.26505/DJM.18025200119

\footnotetext{
${ }^{1}$ Environmental Research Center- University of Technology-Baghdad-Iraq.
}

\section{Introduction}

Chronic myeloid leukemia (CML) is infrequent type of neoplasia with incidence of 1-2 patients per 100,000 people. CML is

described by clonal development of hematopoietic progenitor cells, producing increased circulating cells of granulocytic 
progenitors. The typical symptoms of this disorder are chronic weakness, fever, weight loss, bleeding, and; whereas signs are anemia, splenomegaly, granulocytosis, immature granulocytes, the appearance of basophils, and thrombocytosis [1]. CML distinguished by rearrangement of the long arms of both chromosomes 9 and 22, lead to formation of Philadelphia $(\mathrm{Ph})$ chromosome, as a result of this reunion produce, BCR/ABL1 tyrosine kinase [2]. Cytogenetic is very important tool, for the diagnosis, prediction and therapy of neoplasms like CML $[3,4]$. The BCR/ABL translates to a protein of $\mathrm{Mr} 210,000$, the $\mathrm{BCR} / \mathrm{ABL}$ oncoprotein is located in the cytoplasm and causes activated tyrosine kinase [5]. Like to other type of kinases, the main function $\mathrm{BCR} / \mathrm{ABL}$ is to bind with ATP and transfers phosphate from ATP to residues of tyrosine [6]. This product causes excessive proliferation of cells, turning off apoptosis, and inhibition of cellular adhesion [7]. It is obvious that the CML pathogenesis is associated with the enhanced tyrosine kinase of BCR/ABL protein [8]. Clinically, CML passed through three featured periods the first one is chronic phase it is easy to suppress the disease in this stage followed by unsettled accelerated phase, finally the neoplastic phase [9-11]. The most of CML patients display the $\mathrm{Ph}$ - chromosome as the unique alteration during the chronic phase [12]. In advanced phases, neoplastic cells show new chromosomal abnormalities, it may be a modified version of the $\mathrm{Ph}$ - chromosome i(17q), and trisomy of 19 and may be 8 [13].
The growing of genetic instability of the leukemic cells accelerates to appear of subclones of highly oncogenic phenotypes, but observing cytogenetic and molecular responses to therapy developed as a good indicator to deal with a long-term disease. The CCR is determined as the loss of $\mathrm{Ph}+$ cells in at least 20 bone marrow cells examined in the metaphases stage. Patients with active cytogenetic or molecular remission and $\mathrm{CCR}$ have affirmative prognosis; more than $70 \%$ of them remain alive after 10 years. A karyotype is important in post-remission treatment choice and the molecular indicator will define treatment in individuals with normal karyotype. Extreme monitoring can have a high economic cost, but treatment failure may result in the quickening of the disease or death of the patient [14]. The present study was conducted from April/2018 to October/ 2019 aims to identify the secondary chromosomal aberrations associated with the CML in Iraqi patients have positive $\mathrm{Ph}$ - chromosome at different phases of the disease.

\section{Patients and Methods}

This study which was continued from April /2018 to October/ 2019, included 75 CML Iraqi patients, conducted in Al-Kadumyha Teaching Hospital and Tissue Culture and Immunochemistry Lab/ University of Technology. Briefly, the eligible patients were male or female $\leq 18$ years of old and had confirmative diagnosis of CML with positive assay for $\mathrm{Ph}$ - chromosome $\mathrm{t}(9: 22)(\mathrm{q} 34: \mathrm{q} 11.2)$. Also patients with $\mathrm{BCR} / \mathrm{ABL}$ positive. The first chronic stage 
was distinguished by presence of $30 \%$ blasts with promyelocytes within blood and marrow, $20 \%$ basophil and $15 \%$ blasts, while counting of platelet over than 100000/mm3. Accelerated phase was detected by $>30 \%$ blasts with promyelocytes in bone marrow and peripheral blood, $\leq 30 \%$ blasts and $15 \%$ basophils in blood while platelet count still $\leq 100000 / \mathrm{mm} 3$. The current investigation was carried out according to the Declaration of Helsinki, with our concern to obtain written approvals from the study patients according to institutional guidelines. The rules were evaluated and approved by an Institutional Review Ethical Committee at each contributing center.

\section{Cytogenetic analyses}

Chromosomal analyses were conducted at metaphase stage for bone marrow derived cells, by using short- term technique. Briefly, $10 \mu \mathrm{g} / \mathrm{mL}$ of colcemide was added to culture media (RPMI-1640) and left in $37^{\circ} \mathrm{C}$ in $\mathrm{CO} 2$ incubator for one hour, after that bone marrow cells were incubated for 20 minutes at hypotonic solution (0.075 M KCL), then, cells were fixed with fixative solution ( $1: 3$ glacial acetic acid to absolute methanol). The remain pellet was dropped on clean cold slide and left to dry at room temperature. All slides were stained with G- banding technique. The chromosomal abnormalities were recorded by karyotypes according to human cytogenetic nomenclature system for pretreated patients and every twelve weeks beyond beginning of therapy $[15,16]$.

\section{Results}

The experimental group contains 75 patients with main age $42 \pm 8.7$ years, male to female ratio was $(1.7: 1)$, males number were 48 with percentage about $64 \%$, while females number were 27 with percentage about $36 \%$, the characteristics of patients were summarized in Table (1).

Table (1) : Characteristics and Disease Feature for CML Patients

\begin{tabular}{||l||l||}
\hline \multicolumn{1}{|c|}{ Variables } & \multicolumn{1}{c|}{ Value } \\
\hline \hline Total patients & 75 \\
\hline \hline Sex $\mathrm{n} \%$ & $\begin{array}{l}\text { Male }=48,64 \% \\
\text { female }=27,36 \%\end{array}$ \\
\hline \hline Age & Mean $=42$, \\
& Standard deviation $=8.7$ \\
\hline \hline Phase & $\mathrm{CP}=35$ \\
& $\mathrm{AP}=27$ \\
\hline \hline WBC count & $\mathrm{BP}=13$ \\
\hline \hline Platelet count & $125,000 \pm 22,000$ cell $/ \mathrm{mm}^{3}$ \\
\hline \hline
\end{tabular}

Chromosomal analyses of the $75 \mathrm{CML}$ patients $(89.3 \%)$. In 8 cases, the $\mathrm{Ph}$ cases showed the existence of the ideal $\mathrm{Ph}$ chromosome founded by multiple alterations chromosome, $\mathrm{t}$ (9: 22) (q34:q11.2), in 67 of translocations involving chromosomes 22 
and 9, eight cases were absence the $\mathrm{Ph}$ chromosome, but FISH assay showed $\mathrm{BCR} / \mathrm{ABL}$ gene fusion localized on the $22 \mathrm{q}$. Beside of the Ph-chromosome, all 75 of the cases revealed additional derivative Structural and/or numerical aberrations. These aberrations demonstrated particularly in the Ph-clone in most of the cases, as a sign of clonal progression. Most of the patients revealed the main pathways of CML karyotypic development involving the hallmark $\mathrm{Ph}$-chromosome in 67 patients, trisomy 19 in 5 cases, trisomy 8 in 15 cases, trisomy 21 in two cases in addition to isochromosome $17 \mathrm{q}$ in 7 cases, while less frequent aberrations noted were losing of $17 \mathrm{p}$ in 6 patients loses or rearrangement of ch- 7 in 3 patients, rearrangement of chromosome 13 (frequently 13p) in 8 cases, and $11 p$ in 3 cases. Through blastic phase transformation of one case had an inversion of chromosome 16, inv. 16(p13q22), other cases revealed translocation (15: 17) (q22: q25) as secondary abnormalities. From FISH assay duple-dye $\mathrm{pml} / \mathrm{rara}$ DNA probes, this means pml gene translocate to ch-17 without fusion with rara gene, not as found in acute myelocytic leukemia (AML) $t$ (not as found in 15: 17) is real fusion between $\mathrm{pml} / \mathrm{rara}$ genes, all primary and secondary chromosomal alterations were summarized in Table (2), 55 patients demonstrated one or more minor abnormalities with multiple combinations at deferent recurrence. Cytogenetic response (CR) to the therapy was noted in 27 of 75 CML patients (36\%), 15 of $27(55.5 \%)$ at chronic phase, 8of $27(29.6 \%)$ in the accelerated phase, and 4 of $27(14.8 \%)$ at the blastic phase. 12 of those $27 \mathrm{CR}$ cases obtained a complete cytogenetic response one of the 5 patients with advanced disease. Fifteen remain cases divided as the following: 9 with major cytogenetic response and 6 with minor cytogenetic response as shown in Table (2). 
Table(2): Cytogenetics and BCR/ABL FISH Analyses for 27 CML Patients with Cytogenetic Responses

\begin{tabular}{|c|c|c|c|c|c|c|c|}
\hline $\begin{array}{l}\text { Case } \\
\text { No. }\end{array}$ & Phase & $\begin{array}{c}\text { Ph- Ch } \\
\text { status }\end{array}$ & Pre-therapy & $3 m$ & 6m & $9 \mathrm{~m}$ & $\begin{array}{l}\text { Cytogenetic } \\
\text { response }\end{array}$ \\
\hline 1. & $\mathrm{CP}$ & $\mathrm{t}(9: 22)+\mathrm{Ph}$ & $\mathrm{t}(9: 22), \mathrm{t}(9: 11)$ & $12: 20$ & $4: 20$ & $1: 20$ & MCR \\
\hline 2. & $\mathrm{CP}$ & $\mathrm{t}(9: 22)+\mathrm{Ph}$ & $\mathrm{t}(9: 22), \operatorname{inv}(11)$ & $8: 20$ & $3: 20$ & $0: 20$ & CCR \\
\hline 3. & $\mathrm{CP}$ & $\mathrm{t}(9: 22)+\mathrm{Ph}$ & $\mathrm{t}(9: 22),+11 \mathrm{q}$ & 16:20 & $7: 20$ & $2: 20$ & MCR \\
\hline 4. & $\mathrm{CP}$ & $\mathrm{t}(9: 22)+\mathrm{Ph}$ & $\mathrm{t}(9: 22), 8$ & $6: 20$ & $2: 20$ & $0: 20$ & CCR \\
\hline 5. & $\mathrm{CP}$ & $\mathrm{t}(9: 22)+\mathrm{Ph}$ & t $\mathrm{t}(9: 22)$, in $(17)$ & BCR:ABL+ & BCR:ABL- & BCR:ABL- & CCR \\
\hline 6. & $\mathrm{CP}$ & $\mathrm{t}(9: 22)+\mathrm{Ph}$ & $\mathrm{t}(9: 15: 22), 8$ & $4: 20$ & $4: 20$ & $0: 20$ & CCR \\
\hline 7. & $\mathrm{CP}$ & $\mathrm{t}(9: 22)+\mathrm{Ph}$ & $t(9: 22)+8+11$ & $8: 20$ & $6: 20$ & $1: 20$ & MCR \\
\hline 8. & $\mathrm{CP}$ & $\mathrm{t}(9: 22)+\mathrm{Ph}$ & $\mathrm{t}(9: 22)+8-6 \mathrm{q}$ & 18:20 & 11:20 & $1: 20$ & MCR \\
\hline 9. & $\overline{\mathrm{CP}}$ & $\mathrm{t}(9: 22)+\mathrm{Ph}$ & $\mathrm{t}(9: 22), 17 \mathrm{p}$ & 17:20 & 12:20 & $0: 20$ & CCR \\
\hline 10. & $\mathrm{CP}$ & $\mathrm{t}(9: 22)+\mathrm{Ph}$ & $\mathrm{t}(9: 22), \mathrm{t}(9: 11)$ & $15: 20$ & $10: 20$ & $4: 20$ & $\mathrm{mCR}$ \\
\hline 11. & $\mathrm{CP}$ & $\mathrm{t}(9: 22)+\mathrm{Ph}$ & $\mathrm{t}(9: 22), 14 \mathrm{q}$ & 12:20 & $8: 20$ & $1: 20$ & MCR \\
\hline 12. & $\mathrm{CP}$ & $\mathrm{t}(9: 22)+\mathrm{Ph}$ & $t(9: 22), 17 p, 6 q$ & $9: 20$ & $6: 20$ & $0: 20$ & CCR \\
\hline 13. & $\mathrm{CP}$ & $\mathrm{t}(9: 22)+\mathrm{Ph}$ & $\mathrm{t}(9: 15: 22), 8$ & 11:20 & $7: 20$ & $2: 20$ & MCR \\
\hline 14. & $\mathrm{CP}$ & $\mathrm{t}(9: 22)+\mathrm{Ph}$ & $\mathrm{t}(9: 22),+21$ & $17: 20$ & $14: 20$ & $0: 20$ & CCR \\
\hline 15. & $\mathrm{CP}$ & $\mathrm{t}(9: 22)+\mathrm{Ph}$ & 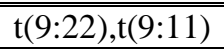 & 15:20 & $111: 20$ & $2: 20$ & MCR \\
\hline 16.16. & AP & $\mathrm{t} \mathrm{t}(9: 22)+\mathrm{Ph}$ & $\begin{array}{l}\mathrm{t}(9: 22)+8-8 \mathrm{q} \\
\end{array}$ & $7: 20$ & $2: 20$ & $2: 20$ & MCR \\
\hline 17. & AP & $\begin{array}{l}\text { BCR/ABL } \\
\text { gene fusion }\end{array}$ & $\mathrm{i}(17) \mathrm{q}+8$ & $8: 20$ & $6: 20$ & $3: 20$ & $\overline{\mathrm{mCR}}$ \\
\hline 18. & AP & $\mathrm{t}(9: 22)+\mathrm{Ph}$ & $\mathrm{t}(9: 22), \mathrm{i}(\mathrm{Ph})$ & BCR:ABL+ & BCR:ABL- & BCR:ABL- & CCR \\
\hline 19. & AP & $\mathrm{t}(9: 22)+\mathrm{Ph}$ & $\mathrm{t}(9: 22), \mathrm{i} 13 \mathrm{q}$ & $11: 20$ & $7: 20$ & $4: 20$ & $\mathrm{mCR}$ \\
\hline 20. & AP & $\mathrm{t}(9: 22)+\mathrm{Ph}$ & $\mathrm{t}(9: 22),+14 q$ & $7: 20$ & $5: 20$ & $3: 20$ & mCR \\
\hline 21. & AP & $\mathrm{t}(9: 22)+\mathrm{Ph}$ & $\mathrm{t}(9: 22),+8 \mathrm{q}$ & $\begin{array}{ll}10: 20 \\
\end{array}$ & $4: 20$ & $0: 20$ & CCR \\
\hline 22. & AP & $\mathrm{t}(9: 22)+\mathrm{Ph}$ & $\mathrm{t}(9: 22),+17 q$ & $20: 20$ & $11: 20$ & $3: 20$ & mCR \\
\hline 23. & AP & $\mathrm{t}(9: 22)+\mathrm{Ph}$ & $\mathrm{t}(9: 15: 22), 8$ & $5: 20$ & $5: 20$ & $2: 20$ & mCR \\
\hline 24. & BP & $\mathrm{t}(9: 22)+\mathrm{Ph}$ & $\mathrm{t}(9: 22), \mathrm{t}(9: 11)$ & $18: 20$ & $12: 20$ & $6: 20$ & mCR \\
\hline 25. & BP & $\mathrm{t}(9: 22)+\mathrm{Ph}$ & $\mathrm{t}(9: 22),+11$ & BCR:ABL- & BCR:ABL- & BCR:ABL- & CCR \\
\hline 26. & BP & $\mathrm{t}(9: 22)+\mathrm{Ph}$ & t $\mathrm{t}(9: 22), 8 \mathrm{p}-$ & $12: 20$ & $7: 20$ & $3: 20$ & mCR \\
\hline 27. & $\mathrm{BP}$ & $\mathrm{t}(9: 22)+\mathrm{Ph}$ & $\mathrm{t}(9: 22), 13 q-$ & $16: 20$ & 9:20 & $6: 20$ & $\mathrm{mCR}$ \\
\hline
\end{tabular}

* Rate ph: standard based on an examination of 20 mitotic cells. BCR:ABL, BCR:ABL+ fusion-positive: BCR:ABL-, BCR:ABL fusionnegative: AP, accelerated phase: $\mathrm{BP}$, blastic phase: $\mathrm{CP}$, chronic phase: $\mathrm{CR}$, cytogenetic response: $\mathrm{CCR}$, complete $\mathrm{CR}$ : MCR, major CR: mCR, minor CR

\section{Discussion}

Practically, the Ph-chromosome in the chronic phase of CML considered a basic genetic phenomenon in most cases and plays a vital role in the evolution and pathogenesis of CML [17]. The BCR/ABL gene fusion is adequate to begin CML, so any therapy can prevent this genetic fault like Imatinib can cause hematological remission in most newly diagnosed CML [18]. Delayed-phase CML, the $\mathrm{Ph}$ - clone can obtain more molecular and/or cytogenetic abnormalities, causes more aggressive phenotypes [19]. Thus, CCR was noted in only $25 \%$ of patients in the accelerated phase and $25 \%$ in the blastic 
phase [20] .The MCR was found in $12.5 \%$ of accelerated phase, it was not seen in the blastic phase, and the current findings refer to a small percentage of patients whose $\mathrm{Ph}$ leukemic cells were a response to imatinib therapy, twenty-seven of the $75 \quad(36 \%)$ patients in this study acquired CRs. Other results have recorded similar CRs in accelerated and blastic phases, through the patient community which has a high repetition of secondary chromosomal aberrations [21, 22]. CRs were showed even in patients who have an extra copy of the $\mathrm{Ph}$ chromosome also noted in some cases with complex abnormalities [23, 24].

Finally, the implications of additional genetic aberrations on clinical response to Imatinib therapy in CML have considerable biological and clinical impacts. The present study recommends that in CML patients with additional chromosomal abnormalities, Imatinib therapy was able to enucleate the $\mathrm{Ph}$ - clone in a small portion of patients [25]. However, in many patients, Imatinib failed to stimulate cytogenetic response suggesting that the $\mathrm{Ph}$ - clone genetically developed and got rid of the dependency on BCR/ABL kinase for proliferation. The limited activity of Imatinib on CML patients with secondary genetic alterations elevates the necessity for conjugation Imatinib with other therapeutic agents to induce treatment outcomes. Nowadays, in vitro studies have shown the synergetic effects of many agents used in joining with Imatinib, and several Phase linked therapy clinical tests have been suggested [24, 25].

\section{Conclusions}

From present findings, can be concluded many CML patients with secondary abnormalities have a weak cytogenetic and molecular response to imatinib therapy so this raises the demand to replace imatinib with other therapeutic agents to enhance treatment outcomes.

\section{Financial Support and Sponsorship}

No fund was received

\section{Conflicts of Interest}

There are no conflicts of interest

\section{References}

[1]Bortolheiro TC, Chiattone CS. Chronic myeloid leukemia: natural history and classification. Rev Bras Hematol Hemoter. 2008: 30(1): 3-7.

[2]Innes AJ, Apperley JF. Chronic myeloid leukemia - transplantation in the tyrosine kinase era. Hematol Oncol Clin North Am. 2014: 28(6): 1037- 53.

[3]Koshiyama DB, Capra ME, Paskulin GA, Rosa RF, Oliveira CA, Vanelli $T$, et al. Cytogenetic response to imatinib treatment in Southern Brazilian patients with chronic myelogenous leukemia and variant Philadelphia chromosome. Ann Hematol. 2013: 92(2): 185-9.

[4]Rumpold H, Webersinke G. Molecular pathogenesis of Philadelphia-positive chronic myeloid leukemia - Is it all BCRABL. Curr Cancer Drug Targets 2011: 11:319.

[5]Radich JP. A primer on molecular testing in chronic myeloid leukemia (PCR for 
Poets). Am J Hematol Onc. 2014: 10(1): 115.

[6]Rowley JD. Chromosome translocations: dangerous liaisons revisited. Nat Rev Cancer. 2001: 1(3): 245-50.

[7]Shtivelman E, Lifshitz B, Gale RP, Canaani E. Fused transcript of ABL and BCR genes in chronic myelogenous leukemia. Nature. 1985: 315: 550-4.

[8]Kim TD, Rea D, Schwarz M, Grille P, Nicolini FE, Rosti G, et al. Peripheral artery occlusive disease in chronic phase chronic myeloid leukemia patients treated with nilotinib or imatinib. Leukemia 2013: 27:1316-21.

[9]Hanfstein B, Müller MC, Hehlmann R, Erben P, Lauseker M, Fabarius A, et al. Early molecular and cytogenetic response is predictive for long-term progression-free and overall survival in chronic myeloid leukemia (CML). Leukemia 2012: 26:2096102.

[10]Alwan AF. Assessment of cytogenetic response after treatment with imatinib mesylate in patients with chronic phase chronic myeloid leukemia. Iraqi J Hematol 2014: 3:56-61.

[11]Taher YM, Almothaffar AM, Matti BF, Alwan AF. Treatment outcome of 100 chronic myeloid leukemia patients using nilotinib as the 2nd line therapy. Iraqi $\mathrm{J}$ Hematol 2018: 7:67-71

[12]Anwar NM, Pamela P, Jeffrey Z, Charles AS. The Effect of Imatinib Mesylate on Patients with Philadelphia Chromosomepositive Chronic Myeloid Leukemia with Secondary Chromosomal Aberrations.
Clinical Cancer Research. 2003: 9: 1333. [13]Bernstein, R. Cytogenetics of chronic myelogenous leukemia. Semin. Hematol.1988. 25: 20-34.

[14]Heim S, Mitelman F. Cancer Cytogenetics. 2nd Ed. New York: WileyLiss, 1995.

[15]Verma R, Babu A. Human chromosomes: Mannual of Basic techniques. Pregramon press, New York. 1989.

[16]ISCN. An International System for Human Cytogenetic Nomenclature. F. Mitelman, Ed. Basel: S Karger, 1995.

[17]Koshiyama DB, Capra MEZ, Paskulin GA, Rosa FM. Cytogenetic response to imatinib treatment in Southern Brazilian patients with chronic myelogenous leukemia and variant Philadelphia chromosome. Ann Hematol. 2013: 92(2): 185-9.

[18]Vigneri P, Wang J. Induction of apoptosis in chronic myelogenous leukemia cells through nuclear entrapment of BCRABL tyrosine kinase. Nat. Med. 2001: 7: 228-234.

[19]Griffen J. The biology of signal transduction inhibition: basic science to novel therapies. Semin. Oncol. 2001: 28: 38.

[20]O'Dwyer ME, Mauro MJ, Kurilik G, Mori M., Balleisen S, Olson S, et al. The impact of clonal evolution on response to imatinib mesylate (STI571) in accelerated phase CML. Blood. 2002: 100: 1628-1633.

[21]Sureda A, Carrasco M, Miguel M, Martinez JA, Conde E, Sanz MA, et al. Imatinib mesylate as treatment for blastic transformation of Philadelphia chromosome 
positive chronic myelogenous leukemia.

Haematologica. 2003: 88:1213-220.

[22]Luize O, Maria HO, Alexandre MD, Jane

D, Eliana A, Luiz FB, et al. The Impact of Additional Chromosomal Abnormalities in Response to Imatinib Mesylate Therapy for Chronic Myeloid Leukemia. Revista Brasileira de Cancerologia 2007: 53(4): 405410.

[23]O'Dwyer ME, Mauro MJ, Blasdel C, Farnsworth M, Kurilik G, Hsieh YC, et al. Clonal evolution and lack of cytogenetic response are adverse prognostic factors for hematological relapse fo chronic phase CML patients treated with imatinib mesylate. Blood. 2004: 103:451-55.

[24]Hochhaus A. Cytogenetic and molecular mechanisms of resistance to imatinib. Semin Hematol. 2003: 40:69-79.

[25]Schoch C, Haferlach T, Kern W, Schnittger S, Berger U, Hehlmann R, et al. Occurrence of additional chromosome aberration in chronic myeloid leukemia patients treated with imatinib mesylate. Leukemia. 2003: 17:461-63. 